\title{
Effects of the flavonol quercetin and $\alpha$-linolenic acid on $n$-3 PUFA status in metabolically healthy men and women: a randomised, double-blinded, placebo-controlled, crossover trial
}

\author{
Constanze Burak ${ }^{1}$, Siegfried Wolffram ${ }^{2}$, Berndt Zur ${ }^{3}$, Peter Langguth ${ }^{4}$, Rolf Fimmers ${ }^{5}$, Birgit Alteheld ${ }^{1}$, \\ Peter Stehle ${ }^{1}$ and Sarah Egert ${ }^{1 *}$ \\ ${ }^{1}$ Department of Nutrition and Food Sciences, Nutritional Physiology, University of Bonn, 53115 Bonn, Germany \\ ${ }^{2}$ Institute of Animal Nutrition and Physiology, Christian-Albrechts-University Kiel, 24118 Kiel, Germany \\ ${ }^{3}$ Institute of Clinical Chemistry and Clinical Pharmacology, University Hospital Bonn, 53127 Bonn, Germany \\ ${ }^{4}$ Department of Biopharmaceutics and Pharmaceutical Technology, Institute of Pharmacy and Biochemistry, Johannes \\ Gutenberg University, 55122 Mainz, Germany \\ ${ }^{5}$ Institute of Medical Biometry, Informatics and Epidemiology, University of Bonn, 53105 Bonn, Germany
}

(Submitted 9 September 2016 - Final revision received 5 January 2017 - Accepted 19 January 2017)

\section{Abstract}

Increased dietary intake and tissue status of the long-chain n-3 PUFA, EPA and DHA, is associated with cardiovascular benefits. Epidemiological and animal studies suggest that concomitant nutritive intake of flavonoids may increase the conversion of $\alpha$-linolenic acid (ALA) to longer-chain $n-3$ fatty acids EPA and DHA. We investigated the effects of increased ALA intake on fatty acid composition of serum phospholipids and erythrocytes in metabolically healthy men and women and whether fatty acid profiles and ALA conversion were affected by regular quercetin intake or sex. Subjects $(n$ 74) were randomised to receive at least $3.3 \mathrm{~g} / \mathrm{d}$ ALA with either $190 \mathrm{mg} / \mathrm{d}$ quercetin (ALA + quercetin) or placebo (ALA + placebo) in a double-blinded, placebo-controlled, crossover trial with 8-week intervention periods separated by an 8 -week washout period. A total of seven subjects dropped out for personal reasons. Data from the remaining sixty-seven subjects (thirty-four males and thirty-three females) were included in the analysis. Both interventions significantly increased serum phospholipid ALA (ALA + placebo: $+69 \cdot 3 \%$; ALA + quercetin: $+55 \cdot 8 \%$ ) and EPA (ALA + placebo: $+37 \cdot 3 \%$; ALA + quercetin: +25.5\%). ALA + quercetin slightly decreased DHA concentration by $9.3 \%$. Erythrocyte ALA and EPA significantly increased with both interventions, whereas DHA decreased. Fatty acid composition did not differ between sexes. We found no effect of quercetin. Intake of 3.6 g/d ALA over an 8-week period resulted in increased ALA and EPA, but not DHA, in serum phospholipids and erythrocytes. Neither quercetin supplementation nor sex affected the increment of ALA and relative proportions of $n$-3 PUFA in serum phospholipids and erythrocytes.

Key words: $\boldsymbol{\alpha}$-Linolenic acid: Quercetin: $\boldsymbol{n}$-3 Long-chain PUFA: Sex differences

Epidemiological and clinical studies indicate that high intake of n-3 PUFA may lower the risk for CVD, and studies strongly suggest that $n-3$ PUFA reduces the incidence of cardiovascular outcomes and all-cause-mortality ${ }^{(1-3)}$. Most of these cardioprotective effects are attributed to the marine long-chain $n$-3 PUFA, EPA $(C 20: 5 n-3)$ and DHA $(C 22: 6 n-3)^{(4)}$. Studies on the effects of plant-derived $\alpha$-linolenic acid (ALA; $C 18: 3 n$-3) on CVD risk have revealed inconsistent results ${ }^{(5-8)}$.

ALA is essential for humans because they cannot synthesise it de novo ${ }^{(9)}$. Major dietary sources of ALA include vegetable oils, such as rapeseed and linseed oils, seeds and nuts ${ }^{(8,10,11)}$. ALA serves as a precursor molecule and can be converted into longerchain $n$ - 3 fatty acids, including EPA and DHA. These reactions are catalysed by an enzymatic system involving a series of elongation and desaturation steps. Besides the elongases, the key enzymes are $\Delta^{5}$ - and $\Delta^{6}$-desaturases ${ }^{(9)}$. However, conversion efficiency in human adults is low, with approximately $5 \%$ of ALA converted to EPA and even less $(<1 \%)$ to DHA ${ }^{(4,11,12)}$.

The regulation of PUFA metabolism is not fully understood, although genetic variations, dietary components, nutrientrelated hormonal regulation and substrate competition may alter endogenous fatty acid levels ${ }^{(13)}$. For example, Tang et $a l .{ }^{(14)}$ demonstrated that gene expression regulation of desaturases involves transcription factors such as PPAR $\alpha$.

Data from epidemiological and animal studies suggest that the conversion of ALA to EPA and DHA is increased through simultaneous nutritive intake of flavonoids ${ }^{(15-17)}$. Quercetin $\left(3,3^{\prime}, 4^{\prime}, 5,7-\right.$ pentahydroxyflavone), one of the predominant flavonoids in

Abbreviations: ALA, $\alpha$-linolenic acid; DPA, docosapentaenoic acid.

* Corresponding author: S. Egert, fax +49 228 733217, email s.egert@uni-bonn.de 
human nutrition, is ubiquitously distributed in (edible) plants and is one of the most potent antioxidants of plant origin ${ }^{(18)}$. In addition, experimental studies with quercetin demonstrated that this polyphenol interacts with PPAR $\alpha^{(19,20)}$. Thus, we hypothesised as one potential mechanism that quercetin may influence the activity of $\Delta^{6}$-desaturases and thus increase the fatty acid conversion rates.

In addition, stable isotope tracer studies indicate that the conversion of ALA to DHA is more efficient in females ${ }^{(21-25)}$, which may be explained by greater expression and activity of enzymes (i.e. $\Delta^{6}$-desaturases) and higher oestrogen levels in women ${ }^{(26)}$. These findings in short-term studies using stable isotopes were confirmed by Childs et al. ${ }^{(27)}$, who showed sex-related differences in a long-term intervention with dietary ALA in humans.

To the best of our knowledge, no previous intervention study has examined the effects of ALA and quercetin supplementation on conversion of ALA to long-chain PUFA in humans. Therefore, we conducted a controlled dietary intervention study to investigate, for the first time, whether conversion of nutritive ALA is increased by simultaneous intake of quercetin. Study variables include fatty acid profiles of serum phospholipids and erythrocytes. A second aim was to investigate potential sexrelated differences in ALA conversion and $n$ - 3 PUFA status following ALA supplementation in metabolically healthy, young men and women.

\section{Methods}

\section{Subjects}

Of 250 volunteers (all of whom were university students), 140 attended a screening that included physical assessments (body height and weight, resting blood pressure, heart rate, waist and hip circumference), clinical assessments (liver function, serum lipids and lipoproteins, glucose and haematology), medical history and a dietary questionnaire ( $3 \mathrm{~d}$ food record). Inclusion criteria were non-smoking status, age 19-35 years and BMI $19-25 \mathrm{~kg} / \mathrm{m}^{2}$. Exclusion criteria included fasting serum TAG $\geq 2.26 \mathrm{mmol} / 1(\geq 200 \mathrm{mg} / \mathrm{dl})$, fasting serum LDLcholesterol $\geq 4.14 \mathrm{mmol} / 1$ ( $\geq 160 \mathrm{mg} / \mathrm{dl})$, metabolic or endocrine diseases, malabsorption syndromes, pregnancy and lactation, alcohol abuse, dietary supplements (e.g. polyphenols, fish oil fatty acids or vitamin E) and restrictive dietary requirements. Volunteers with no daily use of vegetable oil and spread in their habitual diet were also excluded.

In all, seventy-four metabolically healthy subjects (thirtyseven women and thirty-seven men) were included in the study. Of them, seven subjects dropped out for personal reasons. Data from the remaining sixty-seven subjects (thirty-three women and thirty-four men) completing the entire study were included in the analysis (per-protocol evaluation). Participant flow from initial screening to final analysis is shown in Fig. 1. Baseline characteristics are presented in Table 1.

The study protocol was explained in detail to the participants, and all of them gave written consent prior to the beginning of the study. The protocol was in accordance with the guidelines of the Declaration of Helsinki and approved by the Ethical Committee of the Medical Faculty of the Rheinische FriedrichWilhelms-Universität Bonn, Germany. The trial was registered at www.germanctr.de/ and http://apps.who.int/trialsearch/as DRKS00005076.

The subjects were instructed to maintain their habitual diet, physical activity levels, lifestyle and body weight throughout the study. Subjects using contraceptives (thirty women) or thyroid drugs ( $n$ 4) were asked to continue taking their medication throughout the study.

\section{Study design and dietary intervention}

The study was conducted in a double-blinded, randomised, placebo-controlled, crossover trial, with two 8-week intervention periods separated by an 8 -week washout period (Fig. 2). During the intervention periods, participants ingested at least $3.3 \mathrm{~g} / \mathrm{d}$ ALA. Subjects were asked to replace their normal margarine or butter with a commercially available rapeseed oilbased margarine (ALA content, $\mathbf{7 . 7 \%}$ of total fatty acids; fat content of margarine, $80 \%$, Goldina; Ostthüringer Nahrungsmittelwerk Gera $\mathrm{GmbH}$ ) and their habitual vegetable oil with refined rapeseed oil (ALA content, $8.8 \%$ of total fatty acids; Brökelmann + Co Ölmühle $\mathrm{GmbH}+\mathrm{Co}$.). To reach the daily ALA amount, participants ingested at least $30 \mathrm{~g}$ of rapeseed oil and $25 \mathrm{~g}$ of rapeseed oil-based margarine. All subjects received a dosage spoon with a $10 \mathrm{~g}$ capacity to calculate their consumption of margarine and oil. To monitor compliance, participants documented daily oil and margarine ingestion in the study diary. The study margarine and oil was provided two times per week and were incorporated into the usual diet of the participants. In addition, all participants were offered bread, buns and stirred cakes that contained rapeseed oil and rapeseed oil-based margarine, which were formulated especially for this study to encourage consumption of the required amount of ALA. Other dietary sources of $n-3$ fatty acids such as fatty fish, $n$-3 fatty acid-enriched foods, fish oil capsules, nuts and seeds were not allowed. For this purpose, study participants were given a detailed list of foods rich in $n-3$ fatty acids.

In addition to the ALA intervention, all participants were supplemented with quercetin (verum) or placebo in the form of hard gelatin capsules. Subjects were instructed to take one capsule with each principal meal for a total of three capsules per day. Capsules were produced at the Institute of Pharmacy and Biochemistry, Johannes Gutenberg University, Mainz, Germany. Quercetin capsules were filled with onion skin extract powder (152 mg per capsule), whereas placebo capsules contained mannitol (approximately $170 \mathrm{mg}$ per capsule). The onion skin extract powder (Allium cepa L; Rudolf Wild GmbH \& Co. KG) contained $45.5 \%$ quercetin, and each capsule contained $63.5 \mathrm{mg}$ of quercetin. The hard gelatin capsules (Coni-Snap ${ }^{\circledR}$ size 3 ) were supplied by Capsugel, and quercetin and placebo capsules were identical in shape and taste. Capsules were filled using a Dott Bonapace semi-automatic capsule-filling machine. Quality was checked by determining the homogeneity of weight distributions in a sample of twenty random capsules from each batch, and the microbiological burden of the capsules was determined after manufacture and before release. The blisters containing twenty capsules of quercetin or placebo were packed into study boxes. The primary investigators, study personnel and participants were 


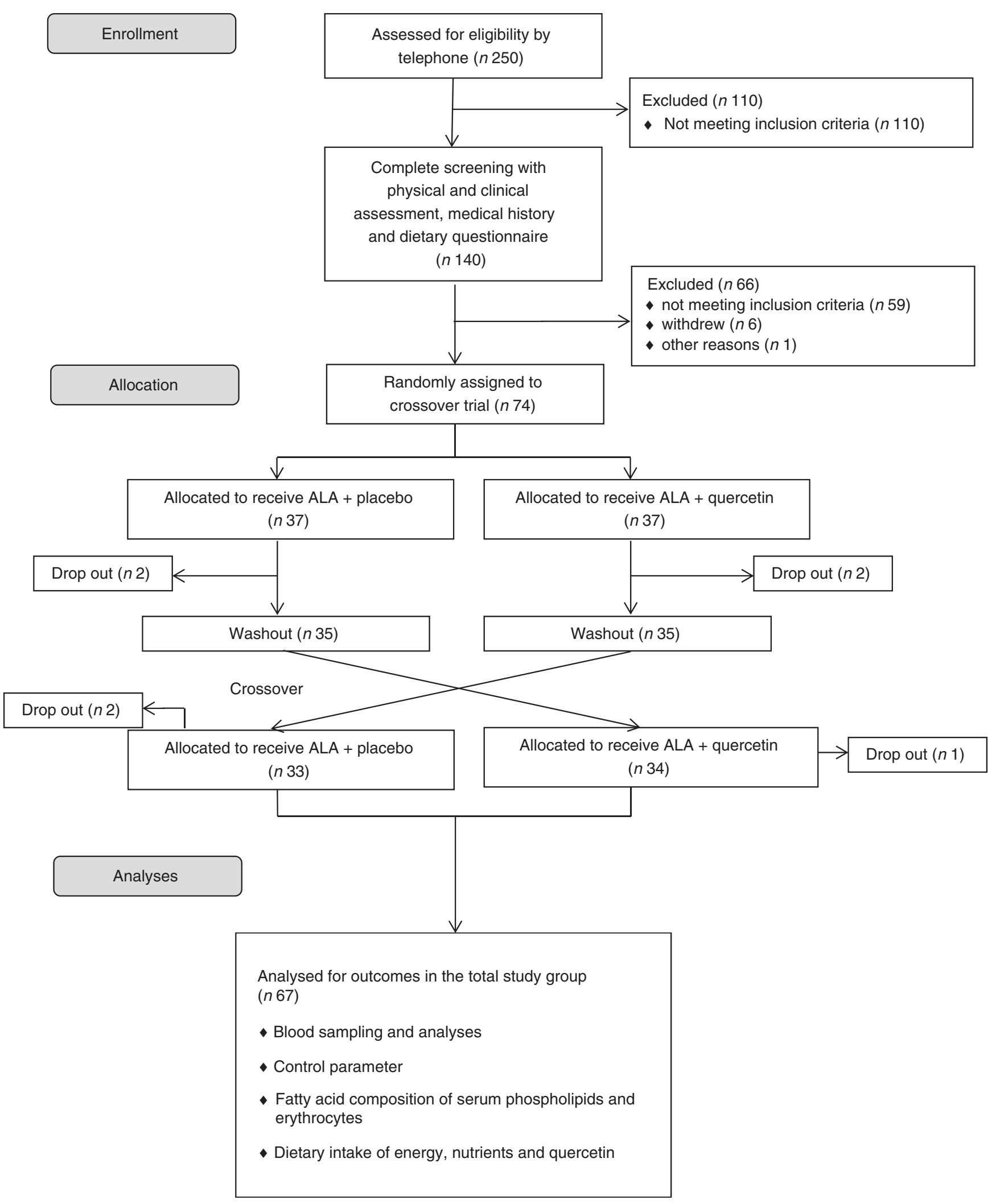

Fig. 1. Flow diagram of participants. ALA, $a$-linolenic acid.

blinded to the treatment. A quercetin dose of $190 \mathrm{mg} / \mathrm{d}$ was selected to represent approximately fifteen times the estimated mean daily quercetin intake in Germany ${ }^{(28)}$ and other European populations ${ }^{(29)}$. The bioavailability of quercetin from onion skin extract and similar quercetin dosages were examined in two previous studies by our research group ${ }^{(30,31)}$. 
Quercetin and $n-3$ fatty acid status

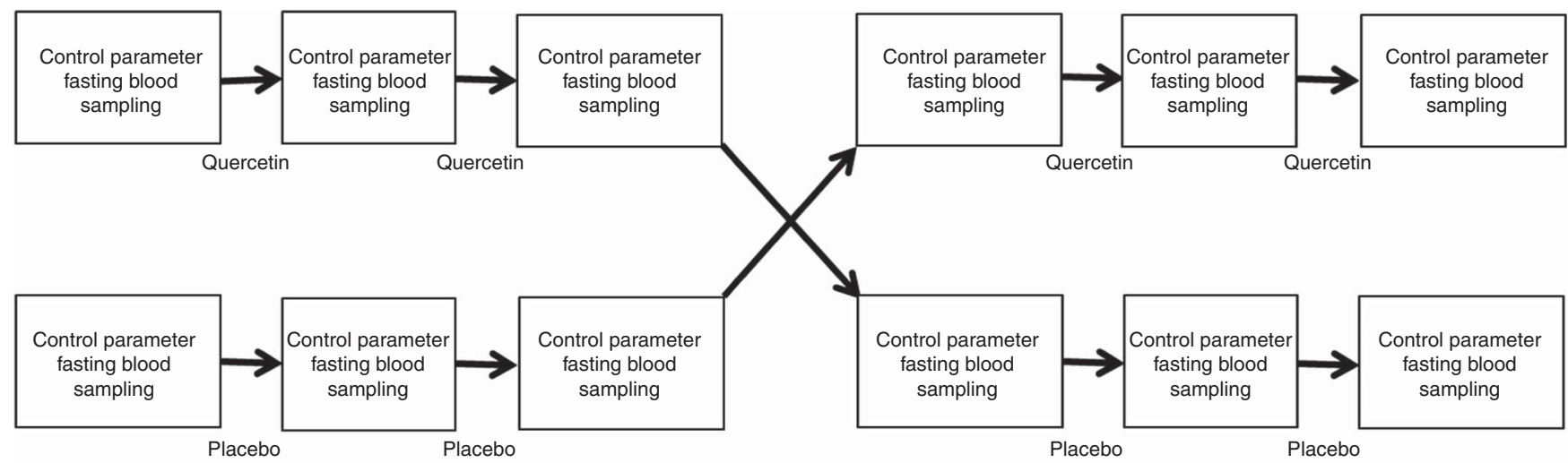

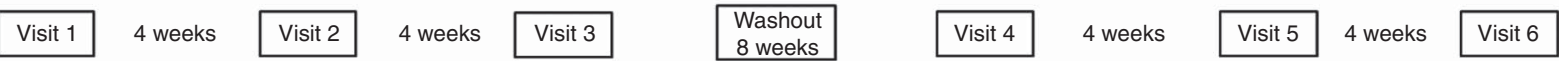

Fig. 2. Study design. Participants ( $n$ 67) were randomly assigned to consume $a$-linolenic acid (ALA) + placebo or ALA + quercetin and consumed the assigned capsules for 8 weeks. After an 8 -week washout period, they crossed over to the alternate treatment.

Subjects were assigned to quercetin or placebo treatment using a block-wise randomisation scheme. Separate computergenerated randomisation schedules for men and women were created to achieve an equal distribution of men and women in each intervention group. Randomisation, allocation to one of the capsule treatments and capsule handling were managed by an independent researcher (B. A.). Study boxes with capsule blisters were distributed on days 0 and 28 of each intervention period at a $20 \%$ surplus. Leftovers and empty blisters were collected on days 28 and 56. Compliance was observed by counting capsules at the end of the study and instructing study participants to document capsule consumption, side effects, physical activity and other relevant observations in the study diary. In addition, we measured plasma quercetin concentrations at the beginning and end of the intervention periods (see below).

Subjects were advised to keep $3 \mathrm{~d}$ food records at the beginning and end of both intervention periods, as well as at the time of screening and during the washout period. Each of the $3 \mathrm{~d}$ food records represented food and beverage intake on 2 weekdays and 1 weekend day and was used to calculate the habitual dietary intake of energy, nutrients, long-chain $n-3$ fatty acids and quercetin.

Sample size was calculated on the basis of an expected increase in serum phospholipid EPA. The power calculation revealed that fifty-one subjects had to complete the study to achieve $80 \%$ power with a significance of $P<0.05$ to detect a change of $6 \%$ between the quercetin and placebo treatments. Assuming a $30 \%$ dropout rate, we aimed to randomly assign seventy-four study participants.

Venous blood sampling and anthropometric measurements were conducted during six study visits (at the beginning, 4-week point and at the end of each intervention period). For each visit, study participants were advised to come to the study centre in the early morning after an overnight fast.

\section{Measurements}

Anthropometrics. Body height was determined on a stadio meter to the nearest $0 \cdot 1 \mathrm{~cm}$. Body weight was recorded to the nearest $100 \mathrm{~g}$. Waist circumference was measured midway between the lowest rib and the iliac crest with the subject at minimal respiration. Hip circumference was measured at the height of the greater trochanters. Body composition was assessed by bioelectrical impedance analysis (Nutriguard-M, Multi Frequency Phase-Sensitive Bioelectrical Impedance Analyzer; Data Input). Fat-free mass was calculated according to Sun et $a l^{(32)}$, and fat mass was calculated by subtracting fat-free mass from body weight.

\section{Blood sample processing and analysis}

Venous blood samples were collected at all visits between 07.00 and 09.30 hours under standardised conditions after an overnight fast. The subjects abstained from alcoholic beverages for $24 \mathrm{~h}$ prior to visits and were advised not to engage in strenuous exercise the day before sampling. The last capsule was taken in the evening before blood sampling. Blood was drawn into tubes containing EDTA, lithium-heparin, fluoride or a coagulation activator (Sarstedt). Plasma and serum were obtained by centrifugation at $3000 \mathrm{~g}$ for $15 \mathrm{~min}$ at $6{ }^{\circ} \mathrm{C}$. The aliquots of plasma and serum were immediately frozen in cryovials and stored at $-80^{\circ} \mathrm{C}$ until analysis. All laboratory measurements were performed without knowledge of the treatment. Serum and plasma samples from one subject were analysed in the same assay run (except for sample analyses in fresh samples, see below).

Clinical safety parameters and haematologic measurements. Clinical safety and haematological parameters were assayed from fresh samples within $4 \mathrm{~h}$ of sampling at the Central Laboratory of the Institute for Clinical Chemistry and Clinical Pharmacology, University Hospital Bonn. Haematological parameters, including erythrocytes, leucocytes, thrombocytes, $\mathrm{Hb}$, haematocrit, mean corpuscular volume, mean corpuscular $\mathrm{Hb}$, mean corpuscular $\mathrm{Hb}$ concentration and mean platelet volume, were determined using fluorescence flow cytometry. The sodium lauryl sulfate (SLS) Hb detection method was 
performed using cyanide-free SLS, and the DC sheath flow detection method was performed using a Sysmex XE-5000 analyzer (Sysmex). Serum alanine transaminase, aspartate transaminase and $\gamma$-glutamyl-transpeptidase were determined using bichromatic kinetic methods, which are adaptions of the methodology recommended by the International Federation of Clinical Chemistry, with a Dimension Vista 1500 analyzer (Siemens Healthcare Diagnostics)

\section{Serum lipid parameters, high-sensitivity C-reactive protein} and sex hormones. Serum concentration of total cholesterol was measured using polychromatic endpoint, whereas serum concentrations of LDL-cholesterol, HDL-cholesterol, TAG, total bilirubin and uric acid, and plasma concentration of glucose were measured using bichromatic endpoint with a Dimension Vista 1500 analyzer (Siemens Healthcare Diagnostics). Serum concentration of urea was measured using VISphotometry with a Dimension Vista 1500 analyzer. Serum concentrations of apo B and A1, albumin and high-sensitivity C-reactive protein were determined using nephelometric methods with a Dimension Vista 1500 analyzer. Serum concentrations of $\mathrm{Na}$ and $\mathrm{K}$ were analysed using the indirect potentiometric V-LYTE multisensory technology method with a Dimension Vista 1500 analyzer. Serum concentrations of progesterone, testosterone, interstitial cell-stimulating hormone and follicle-stimulating hormone were determined by chemiluminescence immunoassay with a Siemens Immulite, and of oestradiol with a Dimension Vista 1500 analyzer (Siemens Healthcare Diagnostics)

Fatty acid composition of serum phospholipids. As a shortterm marker for fatty acid changes, we determined the fatty acid composition of serum phospholipids in duplicate by GC (model 3900; Varian GmbH; flame ionisation detector). After Folch extraction $^{(33)}$ was performed on serum samples, the phospholipid fraction was separated using a silica TLC plate in a solvent mixture of petroleum ether and acetic acid (17:3 by volume $)^{(34)}$. After scraping off the phospholipid band under UV light, the phospholipid fraction was methylated by transesterification with methanol-HCl (25:1 by volume) and incubated at $95^{\circ} \mathrm{C}$ for $4 \mathrm{~h}$. The fatty acid methyl esters were extracted with petroleum ether, dissolved in heptane and injected into the GC. Peaks of interest were identified by comparing with authentic fatty acid methyl ester standards (1,2-diepentadecanoyl-snglycero-3-phosphatidylcholine; Larodan Fine Chemical). Selected fatty acids were expressed as a percentage of the total area by dividing the integrated area under the peak by the total area of all fatty acids. Fatty acids were also determined quantitatively from the internal standard and expressed as $\mu \mathrm{mol} / \mathrm{l}$. The intra-assay CV were $<10 \%$.

Fatty acid composition of erythrocytes. As a long-term marker for fatty acid changes, we determined the fatty acid composition of erythrocytes. Erythrocytes were washed three times with ice-cold isotonic saline to remove the buffy coat, and $1 \mathrm{ml}$ of saline and $20 \mu \mathrm{l}$ of butylhydroxytoluene (0.01\%) in methanol were added to avoid oxidation. Erythrocytes were stored in a $\mathrm{N}_{2}$ atmosphere at $-80^{\circ} \mathrm{C}$ until analysis. Erythrocytes were thawed and haemolysed by adding $1 \mathrm{ml}$ to $1 \mathrm{ml}$ of ice-cold water. Prior to extraction, $340 \mathrm{mg}$ of $\mathrm{NaCl}$ was added. The lipid fraction was extracted using methanol-chloroform (1:2 by volume) according to a modified Folch method ${ }^{(33)}$, methylated using methanol- $\mathrm{HCl}\left(25: 1\right.$ by volume) and incubated at $95^{\circ} \mathrm{C}$ for $4 \mathrm{~h}$. The resulting fatty acid methyl esters were extracted with petroleum ether, dissolved in heptane and injected into the GC. Analyses were conducted in duplicate. The intra-assay CV were $<10 \%$.

\section{Evaluation of $3 d$ food records}

Self-reported intakes of energy, macronutrients, dietary fibre and antioxidant pro-/vitamins were calculated using the computer-based nutrient calculation program EBISpro (University of Hohenheim) based on the German Nutrient Database Bundeslebensmittelschlüssel (Max Rubner-Institute). Quercetin intake was estimated using the US Department of Agriculture flavonoid database ${ }^{(35)}$.

\section{Statistical analyses}

All statistical analyses were performed using IBM SPSS statistical software (SPSS version 21; IBM Corporation). The distribution of variables was analysed by checking normal plots of the data, and Kolmogorov-Smirnov and Shapiro-Wilk tests were performed to test for normality. Differences between sexes at screening were tested using the unpaired Student's $t$ test if data were normally distributed and by the Mann-Whitney $U$ test if data were not normally distributed. Baseline values were compared between groups using paired Student's $t$ tests or Wilcoxon signed-rank tests. Intragroup (baseline $v$. endpoint) and intergroup (changes during quercetin $v$. changes during placebo treatment) comparisons of normally distributed data were performed using paired Student's $t$ tests.

We calculated the treatment difference and examined sexrelated differences between the groups using unpaired Student's $t$ tests. Intra- and intergroup data that were not normally distributed were compared using Wilcoxon signedrank tests. We also performed repeated-measures ANOVA (RMANOVA) for the ALA, EPA and DHA content in the phospholipid fractions. The fixed factors were treatment (two levels: quercetin and placebo) and time of measurement (three levels: weeks 0,4 and 8 of the intervention periods). If the residuals were not normally distributed, RM-ANOVA were conducted with log-transformed variables. In all cases, a value of $P \leq 0.05$ (two-sided) was considered statistically significant. Unless otherwise indicated, descriptive data are presented as arithmetic means and standard deviations. A test for carry-over effects according to Kenward \& Jones ${ }^{(36)}$ was used. No carry-over effects between the two intervention periods could be observed. All analyses are based on a per-protocol basis. Complete data sets were available for all sixty-seven participants. Pearson's correlation coefficients were used to assess relationships between ALA, EPA and DHA in erythrocytes and serum phospholipids (calculated as a percent of total fatty acids) at baseline (week 0) and during the intervention. 


\section{Results}

\section{Subject characteristics at screening}

Characteristics of the participants at screening are presented in Table 1. We observed sex-related differences in body height, body weight, waist circumference, systolic blood pressure, HDL-cholesterol and uric acid (Table 1).

\section{Compliance, dietary intake and consumption of rapeseed oil and margarine}

Count of returned capsules indicated almost full compliance (94.4 (SD 5.8) and 95.6 (SD 5.0)\% for ALA + quercetin and $\mathrm{ALA}+$ placebo consumption, respectively). Compliance with quercetin supplementation was objectively confirmed by a marked increase in fasting plasma concentration of quercetin from 30.4 to $494.7 \mathrm{nmol} / 1$ ( $1660.6 \%$; mean change $+464.2 \mathrm{nmol} / \mathrm{l}$; $P \leq 0.0001)$ and of total flavonols from 50.2 to $570.0 \mathrm{nmol} / 1$ (1065.2\%; mean change, $+519.9 \mathrm{nmol} / 1 ; P \leq 0.0001)$.

Analyses of $3 \mathrm{~d}$ dietary records indicated no significant intraand intergroup differences in mean daily intakes of energy, protein, carbohydrates, total fat, fatty acids, cholesterol, antioxidant vitamins (e.g. vitamin E, vitamin C), dietary fibre and quercetin during the intervention periods (data not shown). The $3 \mathrm{~d}$ dietary records were not significantly different at screening and during the washout periods. Thus, we calculated the habitual diet by averaging the data from both of these records. The percentage of energy derived from protein, carbohydrates and fat, as well as fatty acid intake, differed significantly between the habitual diet and the diet during the interventions (Table 2). As expected, subjects increased consumption of ALA and avoided other sources of long-chain PUFA during the intervention periods.

The mean estimated daily intake of rapeseed oil was 23.7 (sD 7.9) and 23.3 (SD 8.1) g for the ALA + placebo and ALA+ quercetin interventions, respectively. Mean estimated daily intake of margarine was 24.2 (SD 9.8) and 24.1 (SD 8.9) $\mathrm{g}$ for the
ALA + placebo and ALA + quercetin interventions, respectively. The mean daily ALA intake from rapeseed oil and margarine was 3.6 (SD 0.8) $\mathrm{g}$ and did not differ between intervention groups. Total ALA intake (which included the contribution from the remainder of the diet) was $2 \cdot 16 \%(5.4 \mathrm{~g} / \mathrm{d})$ and $2.17 \%$ $(5.4 \mathrm{~g} / \mathrm{d})$ of energy for ALA + placebo and ALA + quercetin interventions, respectively. The reported daily energy and nutrient intakes during the intervention periods are presented in Table 2

\section{Body weight, waist and hip circumference, body composition and safety parameters}

Body weight, waist and hip circumference, relative fat mass and fat-free mass remained constant throughout the study (data not shown). Biomarkers of liver and renal function (ALT, AST, GGT, bilirubin, albumin, creatinine, urea and uric acid), haematology, serum electrolytes and sex hormones were within normal ranges at all time points and were not different between the groups (data not shown).

\section{Fatty acid composition of serum phospholipids}

Fatty acid composition was not different between the two groups at baseline. ALA supplementation of a duration of 8 weeks led to 69.3 and $55.8 \%$ increases in serum phospholipid ALA concentration in the ALA + placebo and ALA + quercetin interventions, respectively (both $P \leq 0 \cdot 0001$; Table 3). Moreover, EPA concentration increased with both interventions $(37.3 \%$ for ALA + placebo; $P=0.001$ and $25.5 \%$ for ALA + quercetin; $P=0.048$ ), and the increases in ALA and EPA concentration were similar between the interventions. DHA concentration decreased by $9.3 \%$ with ALA + quercetin $(P=0.0002)$ and was significantly different from the decrease in the ALA + placebo group $(P=0 \cdot 021)$. However, the pattern of change in ALA, EPA and DHA concentration differed over the

Table 1. Subject characteristics and blood parameters at screening (Mean values and standard deviations)

\begin{tabular}{|c|c|c|c|c|c|c|c|}
\hline & \multicolumn{2}{|c|}{ Total ( $n$ 67) } & \multicolumn{2}{|c|}{ Women (n 33) } & \multicolumn{2}{|c|}{ Men ( $n$ 34) } & \multirow[b]{2}{*}{ Women $v$. men $(P)^{*}$} \\
\hline & Mean & SD & Mean & SD & Mean & SD & \\
\hline Age (years) & $24 \cdot 6$ & 3.9 & $24 \cdot 1$ & $2 \cdot 8$ & $25 \cdot 0$ & $4 \cdot 8$ & 0.930 \\
\hline Body height $(\mathrm{cm})$ & $174 \cdot 1$ & $8 \cdot 8$ & $168 \cdot 4$ & $6 \cdot 2$ & $179 \cdot 7$ & $7 \cdot 3$ & $\leq 0.0001$ \\
\hline Body weight (kg) & $67 \cdot 7$ & 10.9 & $60 \cdot 3$ & $7 \cdot 0$ & 74.9 & 8.9 & $\leq 0.0001$ \\
\hline BMI $\left(\mathrm{kg} / \mathrm{m}^{2}\right)$ & $22 \cdot 2$ & $2 \cdot 3$ & $21 \cdot 3$ & $2 \cdot 2$ & $23 \cdot 2$ & $2 \cdot 1$ & 0.001 \\
\hline Waist circumference $(\mathrm{cm})$ & $80 \cdot 6$ & $6 \cdot 8$ & $78 \cdot 3$ & 6.5 & 82.9 & $6 \cdot 4$ & 0.002 \\
\hline Hip circumference (cm) & 89.9 & $5 \cdot 4$ & 88.7 & $5 \cdot 2$ & $91 \cdot 1$ & 5.5 & 0.077 \\
\hline Waist:hip ratio & 0.89 & 0.06 & 0.88 & 0.06 & 0.91 & 0.05 & 0.085 \\
\hline Systolic BP (mmHg) & $130 \cdot 9$ & $14 \cdot 6$ & 123.9 & $12 \cdot 8$ & $137 \cdot 7$ & $13 \cdot 0$ & $\leq 0.0001$ \\
\hline Diastolic BP (mmHg) & $84 \cdot 1$ & $9 \cdot 5$ & $83 \cdot 2$ & $10 \cdot 6$ & $85 \cdot 0$ & $8 \cdot 4$ & 0.286 \\
\hline Heart rate (min) & $72 \cdot 1$ & $13 \cdot 8$ & $75 \cdot 3$ & $13 \cdot 8$ & $69 \cdot 1$ & $13 \cdot 3$ & 0.132 \\
\hline Serum TAG $(\mathrm{mmol} / \mathrm{l})$ & 1.09 & 0.60 & $1 \cdot 14$ & 0.46 & 1.04 & 0.71 & 0.051 \\
\hline Serum total cholesterol $(\mathrm{mmol} / \mathrm{l})$ & 4.59 & 0.80 & $4 \cdot 75$ & 0.69 & 4.44 & 0.87 & 0.117 \\
\hline Serum HDL-cholesterol (mmol/l) & 1.61 & 0.42 & 1.77 & 0.44 & 1.45 & 0.33 & 0.001 \\
\hline Serum LDL-cholesterol (mmol/l) & $2 \cdot 60$ & 0.66 & 2.56 & 0.64 & 2.63 & 0.70 & 0.693 \\
\hline Plasma glucose (mmol/l) & 4.58 & 0.41 & 4.53 & 0.35 & 4.64 & 0.45 & 0.293 \\
\hline Uric acid $(\mu \mathrm{mol} / \mathrm{l})$ & 241.55 & $72 \cdot 78$ & $187 \cdot 19$ & 38.90 & $292 \cdot 70$ & $58 \cdot 74$ & $\leq 0.0001$ \\
\hline
\end{tabular}

BP, blood pressure.

* Unpaired Student's $t$ test or Mann-Whitney $U$ test. 
Table 2. Reported daily energy and nutrient intakes in healthy men and women during the 8-week supplementation with $a$-linoleic acid (ALA) + placebo or $\mathrm{ALA}+$ quercetin

(Mean values and standard deviations)

\begin{tabular}{|c|c|c|c|c|c|c|c|c|}
\hline & \multicolumn{2}{|c|}{ Habitual diet } & \multicolumn{2}{|c|}{$\begin{array}{c}\text { ALA + placebo } \\
(n 67)\end{array}$} & \multirow{2}{*}{$\begin{array}{l}\text { ALA + placebo } v \text {. } \\
\text { habitual diet }(P) \dagger\end{array}$} & \multicolumn{2}{|c|}{$\begin{array}{c}\mathrm{ALA}+\text { quercetin } \\
(n 67)\end{array}$} & \multirow{2}{*}{$\begin{array}{c}\text { ALA + quercetin } v \text {. } \\
\text { habitual diet }(P) \dagger\end{array}$} \\
\hline & Mean & SD & Mean & SD & & Mean & SD & \\
\hline Total energy $(\mathrm{MJ} / \mathrm{d}) \ddagger$ & $9 \cdot 28$ & 1.94 & 9.80 & $1 \cdot 81$ & 0.074 & 9.79 & $2 \cdot 12$ & $\leq 0.0001$ \\
\hline Protein (En\%) & $16 \cdot 1$ & 3.0 & $14 \cdot 2$ & 2.5 & $\leq 0.0001$ & $14 \cdot 0$ & $2 \cdot 7$ & $\leq 0.0001$ \\
\hline Carbohydrates (En\%) & 41.9 & 5.9 & $40 \cdot 0$ & 4.9 & 0.004 & 39.4 & $5 \cdot 6$ & $\leq 0.0001$ \\
\hline Total fat (En\%) & 39.5 & $5 \cdot 8$ & 43.6 & 4.7 & $\leq 0.0001$ & 44.9 & 5.5 & $\leq 0.0001$ \\
\hline SFA (En\%) & $16 \cdot 0$ & 3.5 & 13.4 & $2 \cdot 7$ & $\leq 0.0001$ & $13 \cdot 6$ & $2 \cdot 9$ & $\leq 0.0001$ \\
\hline MUFA (En\%) & 13.9 & $2 \cdot 3$ & $19 \cdot 6$ & $2 \cdot 6$ & $\leq 0.0001$ & $20 \cdot 4$ & 3.0 & $\leq 0.0001$ \\
\hline PUFA (En\%) & $6 \cdot 8$ & $2 \cdot 2$ & 8.7 & 1.4 & $\leq 0.0001$ & 8.9 & 1.4 & $\leq 0.0001$ \\
\hline$n-6$ PUFA (En\%) & 5.78 & 1.85 & 6.47 & $1 \cdot 10$ & 0.001 & $6 \cdot 68$ & $1 \cdot 10$ & $\leq 0.0001$ \\
\hline $18: 2(n-6)(\mathrm{g} / \mathrm{d})$ & $13 \cdot 76$ & $6 \cdot 28$ & $16 \cdot 07$ & 4.22 & $\leq 0.0001$ & $16 \cdot 46$ & 4.30 & $\leq 0.0001$ \\
\hline $20: 4(n-6)(g / d)$ & 0.14 & 0.09 & 0.11 & 0.07 & 0.031 & 0.15 & 0.14 & 0.681 \\
\hline$n-3$ PUFA (En\%) & 1.03 & 0.59 & $2 \cdot 22$ & 0.43 & $\leq 0.0001$ & $2 \cdot 24$ & 0.42 & $\leq 0.0001$ \\
\hline $18: 3(n-3)(\mathrm{g} / \mathrm{d})$ & $2 \cdot 21$ & 1.47 & 5.41 & 1.40 & $\leq 0.0001$ & 5.39 & 1.34 & $\leq 0.0001$ \\
\hline $20: 5(n-3)(g / d)$ & 0.06 & 0.09 & 0.02 & 0.05 & 0.003 & 0.03 & 0.08 & 0.003 \\
\hline $22: 6(n-3)(\mathrm{g} / \mathrm{d})$ & 0.17 & 0.20 & 0.09 & 0.10 & $\leq 0.0001$ & 0.11 & 0.18 & 0.023 \\
\hline$n-6: n-3$ PUFA ratio & $6 \cdot 29$ & $2 \cdot 31$ & 2.97 & 0.48 & $\leq 0.0001$ & 3.04 & 0.53 & $\leq 0.0001$ \\
\hline LA:ALA ratio & 6.9 & 2.5 & 3.0 & 0.5 & $\leq 0.0001$ & 3.1 & 0.5 & $\leq 0.0001$ \\
\hline Dietary fibre (g/MJ) & 2.66 & 0.96 & 2.42 & 0.73 & 0.004 & $2 \cdot 38$ & 0.77 & $\leq 0.0001$ \\
\hline Quercetin (mg/d) & 7.5 & $5 \cdot 7$ & $8 \cdot 7$ & $6 \cdot 3$ & 0.036 & $7 \cdot 7$ & $5 \cdot 0$ & 0.580 \\
\hline Vitamin E (mg/MJ)§ & 1.61 & 0.46 & 2.32 & 0.38 & $\leq 0.0001$ & 2.42 & 0.43 & $\leq 0.0001$ \\
\hline
\end{tabular}

En\%, energy percent; LA, linoleic acid.

$\dagger$ Unpaired Student's $t$ test or Mann-Whitney $U$ test.

$\ddagger$ To convert to kcal/d multiply by 239 .

$\S a$-Tocopherol equivalents.

course of the intervention. ALA was only significantly increased over the first 4 weeks in both groups (both $P \leq 0 \cdot 0001$, Fig. 3), and the EPA increase was only significant during the first 4 weeks in the ALA + placebo group $(P=0.005)$ (Fig. 4). DHA decreased significantly over the first 4 weeks in the ALA + quercetin group $(P=0 \cdot 0001)$ (Fig. 5). Overall, we observed no sex-related differences in changes in ALA, EPA and DHA concentration in serum phospholipid fatty acids from week 0 to week 8 . We observed a significant decrease in the $n-6$ fatty acid, arachidonic acid (AA), in the ALA + quercetin group $(P=0.003)$.

Similarly, the percentage distribution of ALA $(P \leq 0.0001$ for both treatments) and EPA $(P \leq 0.0001$ for ALA + placebo and $P=0.007$ for ALA + quercetin) increased significantly (Table 3), whereas the percentage distribution of DHA decreased in the ALA + quercetin group $(P=0 \cdot 016)$. Percentage stearidonic acid decreased $(P=0.011$ for ALA + placebo and $P=0.0002$ for $\mathrm{ALA}+$ quercetin) and percentage docosapentaenoic acid (DPA) increased with both interventions $(P=0.006$ for ALA + placebo and $P=0.0001$ for ALA + quercetin), although no significant intergroup effects were observed.

Serum phospholipid fatty acid profiles were not different between men and women at baseline, after the two treatments, or over the course of the treatment (change from week 0 to week 8) (data not presented).

\section{Fatty acid composition of erythrocytes}

After 8 weeks, erythrocyte ALA content increased by $48.6 \%$ $(P \leq 0.0001)$ with the ALA + placebo intervention and by $45.8 \%$ $(P \leq 0.0001)$ with the ALA + quercetin intervention (Table 4). EPA increased by $12.7 \%$ in the ALA + quercetin group
( $P=0.008)$. DHA decreased by $2.9 \%$ with both treatments ( $P=0.005$ for ALA + placebo and $P=0.001$ for ALA + quercetin). DPA increased by $3.8 \%$ in the ALA + placebo group $(P=0.003)$ and by $4.5 \%$ in the ALA + quercetin group $(P \leq 0.0001)$ (Table 4). However, intergroup comparisons did not show an effect of adding quercetin to ALA, and neither treatment significantly affected the content of ( $n$-6) fatty acids linoleic acid (LA) and AA in erythrocytes (Table 4). Erythrocyte fatty acid profiles were not different between men and women at baseline, after the two treatments, or over the course of the treatment (from week 0 to week 8) (data not presented).

\section{Correlations}

Baseline erythrocyte content of ALA, EPA and DHA was significantly correlated with baseline percentage fatty acid content in serum phospholipids (for ALA + placebo: ALA, $r 0.59$, $P \leq 0.0001$; EPA, $r 0.54, P \leq 0.0001$; DHA, $r 0.76, P \leq 0.0001$ and for ALA + quercetin: ALA, $r$ 0.56, $P \leq 0.0001$; EPA, $r \quad 0.67$, $P \leq 0.0001$; DHA, $r 0.79, P \leq 0.0001)$. In addition, fatty acid changes in erythrocytes were significantly correlated with changes in serum phospholipids (ALA + placebo: ALA, $r$ 0.61, $P \leq 0.0001$; EPA, $r 0.44, P=0.0002$; DHA, $r 0.55, P \leq 0.0001$ and ALA +quercetin: ALA, $r 0.50, P \leq 0.0001$; EPA, $r 0.35$, $P=0.004$; DHA, $r 0.39, P=0.001)$. The increase in erythrocyte EPA content was negatively correlated with erythrocyte EPA content at baseline (ALA+ placebo: $r-0.343, P=0.004$ and ALA + quercetin: $r-0.495, P \leq 0.0001)$. Thus, the erythrocyte EPA content at baseline and the change in erythrocyte EPA content were related, as individuals with lower baseline 


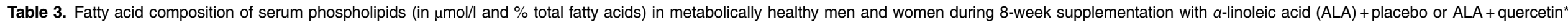
(Mean values and standard deviations)

\begin{tabular}{|c|c|c|c|c|c|c|c|c|c|c|c|c|c|c|c|c|c|}
\hline & \multicolumn{6}{|c|}{ ALA + placebo $(n 67)$} & \multicolumn{7}{|c|}{ ALA + quercetin $(n 67)$} & \multirow{3}{*}{$\begin{array}{c}P \text { value } \\
\text { intragroup } \\
\text { comparison }\end{array}$} & \multirow{3}{*}{$\begin{array}{c}P \text { value } \\
\text { intergroup } \\
\text { comparison }\end{array}$} & \multirow{2}{*}{\multicolumn{2}{|c|}{$\begin{array}{c}\text { Treatment } \\
\text { difference† }\end{array}$}} \\
\hline & \multicolumn{2}{|c|}{ Baseline } & \multicolumn{2}{|c|}{ Endpoint } & \multicolumn{2}{|c|}{ Mean change } & \multirow{2}{*}{$\begin{array}{c}P \text { value } \\
\text { intragroup } \\
\text { comparison }\end{array}$} & \multicolumn{2}{|c|}{ Baseline } & \multicolumn{2}{|c|}{ Endpoint } & \multicolumn{2}{|c|}{ Mean change } & & & & \\
\hline & Mean & SD & Mean & SD & Mean & SD & & Mean & SD & Mean & SD & Mean & SD & & & Mean & SD \\
\hline \multicolumn{18}{|l|}{ Fatty acids $(\mu \mathrm{mol} / \mathrm{l})$} \\
\hline Total SFA & 1978.25 & 418.90 & 1924.07 & 416.03 & -54.18 & 318.46 & 0.168 & 2074.54 & 507.55 & 1895.07 & 419.92 & $-179 \cdot 47$ & 410.63 & 0.001 & 0.040 & $-125 \cdot 29$ & 489.15 \\
\hline $16: 0$ & 1341.00 & 307.98 & 1275.90 & 317.53 & -65.10 & 223.54 & 0.020 & 1410.49 & 377.74 & 1250.00 & 321.93 & -160.50 & 287.03 & $\leq 0.0001$ & 0.026 & -95.40 & 342.84 \\
\hline $18: 0$ & 487.23 & 103.72 & 497.22 & 92.62 & 9.99 & 88.68 & 0.360 & $505 \cdot 86$ & 119.03 & 497.88 & 100.83 & -7.98 & 118.83 & 0.764 & 0.226 & -17.97 & 137.71 \\
\hline Total MUFA & 413.26 & $102 \cdot 32$ & $424 \cdot 14$ & $95 \cdot 19$ & +10.89 & 71.08 & 0.159 & $440 \cdot 16$ & 109.93 & 423.19 & 99.41 & -16.97 & 96.58 & 0.273 & 0.023 & -27.86 & 114.73 \\
\hline $18: 1(n-9)$ & 296.59 & 76.06 & 301.20 & 68.21 & +4.61 & 56.86 & 0.509 & $312 \cdot 14$ & 83.39 & 297.87 & 74.54 & $-14 \cdot 27$ & 77.84 & 0.138 & 0.106 & -18.88 & 94.27 \\
\hline Total PUFA & 1796.41 & 398.03 & 1744.99 & 382.36 & -51.42 & 282.72 & 0.141 & $1852 \cdot 46$ & 430.75 & 1732.46 & 369.45 & -120.00 & 349.99 & 0.007 & 0.188 & -68.58 & 422.40 \\
\hline Total $(n-6)$ PUFA & $1581 \cdot 17$ & $335 \cdot 17$ & 1520.43 & 322.50 & -60.75 & 254.25 & 0.055 & 1630.01 & 373.17 & 1521.09 & 312.42 & -108.92 & 319.66 & 0.007 & 0.306 & -48.18 & 382.17 \\
\hline $18: 2(n-6)$ & 943.96 & $215 \cdot 68$ & 913.28 & 188.51 & -30.68 & 177.22 & 0.161 & 957.47 & 216.06 & 918.32 & 188.47 & -39.09 & 212.06 & 0.136 & 0.795 & -8.41 & $264 \cdot 17$ \\
\hline $20: 4(n-6)$ & 468.38 & 122.00 & 453.59 & $120 \cdot 11$ & -14.79 & 80.78 & 0.139 & 493.09 & 147.54 & 455.00 & 121.06 & -38.08 & 101.77 & 0.003 & 0.124 & $-23 \cdot 30$ & $122 \cdot 29$ \\
\hline Total $(n-3)$ PUFA & $215 \cdot 23$ & 82.85 & 224.56 & 78.09 & +9.33 & 49.83 & 0.130 & 222.44 & 81.03 & 211.37 & 74.99 & -11.07 & 57.70 & 0.121 & 0.031 & -20.40 & 75.99 \\
\hline $18: 3(n-3)$ & 14.02 & 9.07 & 19.51 & $8 \cdot 13$ & +5.50 & 7.67 & $\leq 0.0001$ & 13.80 & 7.87 & 18.21 & 8.24 & +4.41 & 7.28 & $\leq 0.0001$ & 0.341 & -1.08 & 9.24 \\
\hline $20: 5(n-3)$ & 37.29 & 19.26 & 45.80 & 20.58 & +8.52 & 20.68 & 0.001 & 41.37 & 26.05 & 45.02 & 20.97 & +3.65 & 23.43 & 0.048 & 0.179 & -4.87 & 34.83 \\
\hline $22: 6(n-3)$ & 161.85 & 64.33 & $156 \cdot 77$ & 62.85 & -5.09 & 34.27 & 0.229 & $165 \cdot 15$ & 60.89 & 145.78 & 57.56 & -19.37 & 40.54 & 0.0002 & 0.021 & $-14 \cdot 29$ & 49.41 \\
\hline \multicolumn{18}{|l|}{$\%$ Total fatty acids } \\
\hline Total SFA & $45 \cdot 30$ & $1 \cdot 16$ & 44.99 & $1 \cdot 34$ & -0.31 & 1.02 & 0.014 & $45 \cdot 44$ & 1.00 & 43.50 & 1.88 & -1.94 & 1.59 & $\leq 0.0001$ & $\leq 0.0001$ & -1.62 & 1.81 \\
\hline $16: 0$ & 29.84 & 1.70 & 28.89 & 2.03 & -0.94 & 1.29 & $\leq 0.0001$ & 29.96 & 1.75 & 28.33 & 2.60 & -1.63 & 2.06 & $\leq 0.0001$ & 0.019 & -0.69 & $2 \cdot 30$ \\
\hline $18: 0$ & 11.64 & $1 \cdot 16$ & $12 \cdot 19$ & 1.42 & 0.56 & 0.91 & $\leq 0.0001$ & 11.63 & 1.25 & $12 \cdot 32$ & 1.30 & 0.68 & 1.07 & $\leq 0.0001$ & 0.372 & 0.13 & $1 \cdot 17$ \\
\hline Total MUFA & 14.97 & 1.53 & 15.73 & 1.44 & +0.76 & 1.15 & $\leq 0.0001$ & $15 \cdot 15$ & 1.57 & 15.78 & 1.52 & +0.63 & 1.48 & 0.001 & 0.592 & -0.13 & 2.03 \\
\hline $18: 1(n-9)$ & 10.57 & 1.42 & 10.98 & 1.30 & +0.42 & 1.05 & 0.002 & 10.66 & 1.51 & 10.92 & 1.35 & +0.26 & 1.40 & 0.133 & 0.490 & -0.16 & 1.86 \\
\hline Total PUFA & 39.64 & 1.47 & 39.24 & 1.47 & -0.40 & 1.26 & 0.011 & 39.41 & 1.63 & 39.69 & 1.98 & +0.27 & 1.95 & 0.254 & 0.016 & +0.68 & $2 \cdot 25$ \\
\hline Total $(n-6)$ PUFA & 34.72 & 1.60 & 34.01 & 1.50 & -0.71 & 1.57 & 0.0005 & 34.31 & 1.85 & 34.46 & $2 \cdot 18$ & +0.15 & 2.29 & 0.595 & 0.010 & 0.85 & $2 \cdot 65$ \\
\hline $18: 2(n-6)$ & 21.62 & 2.04 & 21.40 & 1.87 & -0.22 & 2.05 & 0.391 & $21 \cdot 10$ & $2 \cdot 23$ & 21.77 & 2.48 & +0.67 & 2.39 & 0.025 & 0.022 & +0.89 & 3.11 \\
\hline $20: 4(n-6)$ & $9 \cdot 27$ & 1.67 & $9 \cdot 11$ & 1.51 & -0.16 & $1 \cdot 12$ & 0.246 & 9.32 & 1.61 & 9.26 & 1.56 & -0.06 & 0.88 & 0.598 & 0.536 & 0.10 & 1.36 \\
\hline Total $(n-3)$ PÚFA & 4.80 & 0.92 & 5.12 & 0.91 & +0.32 & 0.83 & 0.002 & 4.96 & 1.08 & $5 \cdot 12$ & 0.93 & +0.15 & 0.91 & 0.174 & 0.223 & -0.17 & $1 \cdot 12$ \\
\hline $18: 3(n-3)$ & 0.29 & 0.15 & 0.43 & 0.13 & $+0 \cdot 13$ & 0.14 & $\leq 0.0001$ & 0.28 & 0.13 & 0.40 & 0.13 & +0.12 & 0.14 & $\leq 0.0001$ & 0.510 & -0.01 & 0.18 \\
\hline $18: 4(n-3)$ & 0.09 & 0.03 & 0.08 & 0.03 & -0.01 & 0.03 & 0.011 & 0.09 & 0.04 & 0.08 & 0.03 & -0.02 & 0.03 & 0.0002 & 0.155 & -0.01 & 0.04 \\
\hline $20: 5(n-3)$ & 0.77 & 0.32 & 0.99 & 0.42 & +0.21 & 0.42 & $\leq 0.0001$ & 0.83 & 0.45 & 0.98 & 0.40 & +0.15 & 0.44 & 0.007 & 0.500 & -0.07 & 0.60 \\
\hline $22: 5(n-3)$ & 0.73 & 0.22 & 0.78 & 0.23 & +0.04 & 0.13 & 0.006 & 0.74 & 0.23 & 0.81 & 0.24 & +0.06 & 0.12 & 0.0001 & 0.408 & +0.02 & 0.17 \\
\hline $22: 6(n-3)$ & $2 \cdot 86$ & 0.68 & 2.79 & 0.68 & -0.07 & 0.50 & 0.224 & 2.97 & 0.78 & $2 \cdot 80$ & 0.66 & -0.17 & 0.56 & 0.016 & 0.214 & -0.10 & 0.63 \\
\hline
\end{tabular}

* The two groups did not differ significantly with regard to any of the variables at baseline (paired Student's $t$ tests or Wilcoxon signed-rank tests).

$\dagger$ Treatment difference was calculated by (ALA + quercetin (endpoint - baseline)) - (ALA + placebo (endpoint - baseline)). 


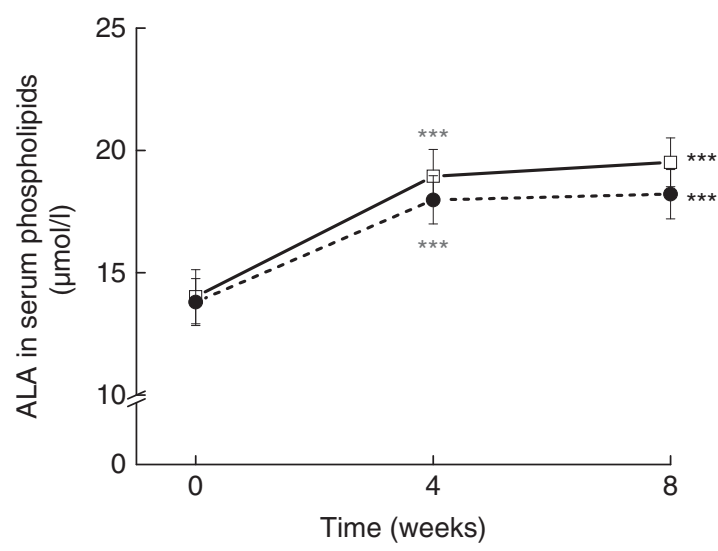

Fig. 3. Time curves of $a$-linolenic acid (ALA) concentration in serum phospholipids in metabolically healthy men and women before, after 4-week and after -week supplementation with -- --, ALA + quercetin $(190 \mathrm{mg} / \mathrm{d})$ and $-\square-$, ALA + placebo ( $n$ 67). Values are means, with their standard errors represented by vertical bars. ${ }^{* \star *}$ Mean value was significantly different from that at baseline ( $P \leq 0.0001$; intragroup comparisons).

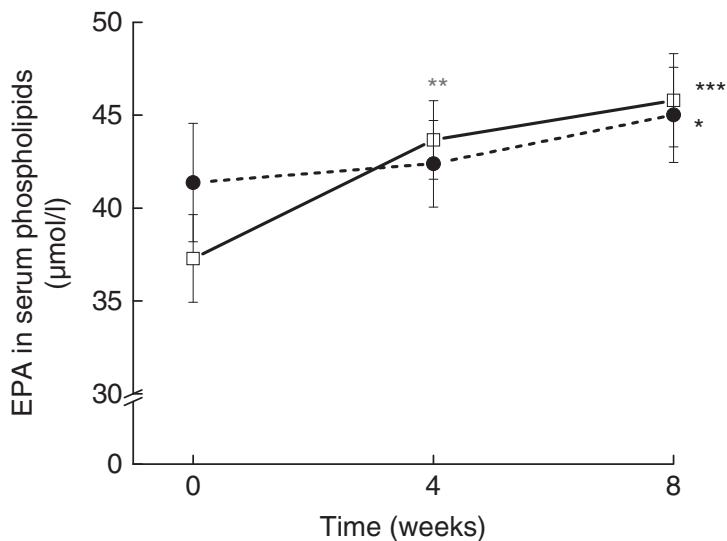

Fig. 4. Time curves of EPA concentration in serum phospholipids in metabolically healthy men and women before, after 4-week and after 8-week supplementation with --- - a $a$-linolenic acid (ALA) + quercetin $(190 \mathrm{mg} / \mathrm{d})$ or $-\square-$, ALA + placebo ( $n$ 67). Values are means, with their standard errors represented by vertical bars. Mean value was significantly different from that at baseline: ${ }^{*} P=0.048,{ }^{\star \star} P=0.005,{ }^{\star \star *} P=0.001$ (intragroup comparisons).

EPA contents demonstrated greater increases in erythrocyte EPA with ALA supplementation (Fig. 6).

\section{Discussion}

The aim of this double-blinded, placebo-controlled, crossover intervention study in metabolically healthy men and women was to investigate whether conversion of ALA, analysed by changes in fatty acid profiles of serum phospholipids and erythrocytes, is influenced by simultaneous intake of quercetin. A second aim was to investigate potential sex-related differences in ALA conversion and $n$ - 3 PUFA status following ALA intake. We showed that increased dietary ALA significantly increased ALA, EPA and DPA, but not DHA, in serum phospholipids and erythrocytes. Changes in the fatty acid composition of erythrocytes, as indicated by relative proportions of ALA, EPA, DPA and DHA, correlated with fatty acid changes in

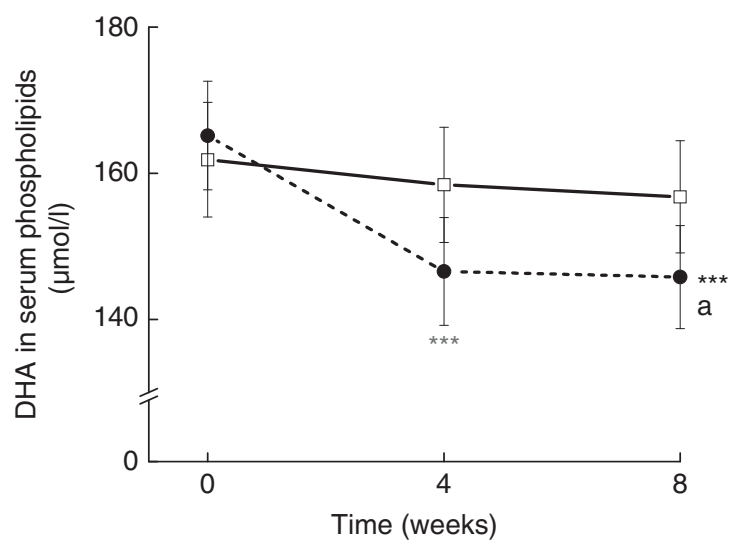

Fig. 5. Time curves of DHA concentration in serum phospholipids in metabolically healthy men and women before, after 4-week and after 8-week supplementation with --- - a -linolenic acid (ALA) + quercetin $(190 \mathrm{mg} / \mathrm{d})$ or $-\square-$, ALA + placebo ( $n$ 67). Values are means, with their standard errors represented by vertical bars. ${ }^{* \star *}$ Mean value was significantly different from that at baseline $(P \leq 0.0001$; intragroup comparisons). † Changes in DHA were significantly different between $A L A+$ placebo and $A L A+$ quercetin $(P=0.021$; intergroup comparison).

serum phospholipids. Contrary to our hypothesis, neither quercetin supplementation nor sex influenced the conversion of ALA to long-chain $n-3$ fatty acids.

\section{Changes in fatty acid profiles}

The intervention significantly increased ALA content in serum phospholipids and erythrocytes, which objectively indicated good compliance and effective incorporation of the ingested $n$-3 fatty acid. The content of EPA and DPA also increased in the serum phospholipids and erythrocytes, indicating the occurrence of metabolic conversion of ALA to EPA and DPA through a series of elongation and desaturation reactions. The increase in EPA and DPA occurred with a daily dose of $3.6 \mathrm{~g}$ of ALA, which represented approximately three times the estimated daily dietary ALA intake (approximately $0.5-1.7 \mathrm{~g}$ ) in most European countries and the USA ${ }^{(10,37,38)}$. We demonstrated that this high dose was easily achieved with regular consumption of ALA-rich rapeseed oil and margarines and did not require dietary supplements.

The significant increase in ALA, EPA and DPA, but not DHA, following ALA intervention is in agreement with earlier ALA intervention studies ${ }^{(25,39-45)}$. The lack of increase in DHA in serum phospholipids and erythrocytes may be because the ALA dose $(3.6 \mathrm{~g} / \mathrm{d})$ was too low to exert a significant increase in DHA. Although ALA is an essential fatty acid for humans, $>60 \%$ and up to $85 \%$ undergoes $\beta$-oxidation and is used as an energy and carbon source ${ }^{(9,38,46)}$. Thus, only a relatively small amount of the ingested ALA undergoes elongation and desaturation and is used for $n$-3 long-chain PUFA synthesis ${ }^{(47,48)}$. Barceló-Coblijn et al. ${ }^{(49)}$ noted that $2.4-3.6 \mathrm{~g} / \mathrm{d}$ ALA for 12 weeks increased EPA, but not DHA, content in erythrocytes, and they concluded that fatty acid composition of erythrocytes is influenced in a doseand time-dependent manner. Results of other studies also confirm that the DHA content in plasma phospholipids does not change with ALA intakes of up to $20 \mathrm{~g} / \mathrm{d}^{(37,41,43)}$, suggesting that 
Table 4. Fatty acid composition of erythrocytes (\% total fatty acids) in metabolically healthy men and women during 8-week supplementation with $a$-linoleic acid (ALA) + placebo or ALA + quercetin

\begin{tabular}{|c|c|c|c|c|c|c|c|c|c|c|c|c|c|c|c|c|c|}
\hline \multirow[b]{3}{*}{$\%$ Total fatty acids } & \multicolumn{6}{|c|}{ ALA + placebo $(n 67)$} & \multicolumn{7}{|c|}{ ALA + quercetin $(n 67)$} & \multirow{3}{*}{$\begin{array}{c}P \text { value } \\
\text { intragroup } \\
\text { comparison }\end{array}$} & \multirow{3}{*}{$\begin{array}{c}P \text { value } \\
\text { intergroup } \\
\text { comparison }\end{array}$} & \multirow{2}{*}{\multicolumn{2}{|c|}{$\begin{array}{l}\text { Treatment } \\
\text { difference† }\end{array}$}} \\
\hline & \multicolumn{2}{|c|}{ Baseline } & \multicolumn{2}{|c|}{ Endpoint } & \multicolumn{2}{|c|}{ Mean change } & \multirow{2}{*}{$\begin{array}{c}P \text { value } \\
\text { intragroup } \\
\text { comparison }\end{array}$} & \multicolumn{2}{|c|}{ Baseline } & \multicolumn{2}{|c|}{ Endpoint } & \multicolumn{2}{|c|}{ Mean change } & & & & \\
\hline & Mean & SD & Mean & SD & Mean & SD & & Mean & SD & Mean & SD & Mean & SD & & & Mean & SD \\
\hline Total SFA & $47 \cdot 11$ & 3.08 & $47 \cdot 25$ & 3.10 & +0.14 & 1.36 & 0.735 & 46.82 & 1.19 & 48.24 & 3.76 & +1.42 & 3.26 & 0.310 & 0.440 & $+1 \cdot 28$ & 4.09 \\
\hline $\begin{array}{l}16: 0 \\
18: 0\end{array}$ & $\begin{array}{l}27.23 \\
12.85\end{array}$ & 1.60 & $\begin{array}{l}26.52 \\
13.44\end{array}$ & 1.42 & -0.71 & 1.17 & $\leq 0.0001$ & 27.67 & $2 \cdot 12$ & 26.62 & 1.64 & -1.05 & 1.55 & $\leq 0.0001$ & 0.192 & -0.34 & 1.76 \\
\hline $18: 0$ & $12 \cdot 85$ & 1.07 & 13.44 & 1.59 & 0.59 & 1.07 & $\leq 0.0001$ & $12 \cdot 86$ & $1 \cdot 18$ & $13 \cdot 29$ & $1 \cdot 34$ & 0.43 & 1.42 & 0.001 & 0.262 & -0.17 & 1.89 \\
\hline Total MUFA & 20.00 & 1.08 & 20.56 & 1.34 & +0.56 & 1.07 & 0.003 & 20.12 & 1.20 & 20.47 & 1.26 & +0.62 & 1.14 & 0.002 & 0.695 & +0.05 & 1.35 \\
\hline $18: 1(n-9)$ & 14.02 & 0.94 & 14.23 & 1.08 & +0.22 & 0.77 & 0.024 & 13.91 & 1.01 & $14 \cdot 31$ & 1.02 & +0.40 & 0.82 & 0.0002 & 0.045 & +0.18 & 0.98 \\
\hline Total PUFA & 33.12 & 1.51 & 32.41 & 1.31 & -0.71 & 1.62 & 0.001 & 32.62 & 1.44 & $32 \cdot 37$ & 1.77 & -0.25 & 1.44 & 0.376 & 0.112 & +0.46 & $2 \cdot 12$ \\
\hline Total $(n-6)$ PUFA & $26 \cdot 33$ & 1.58 & $25 \cdot 84$ & 1.19 & -0.49 & 1.43 & 0.013 & 25.80 & 2.01 & 25.82 & 1.57 & +0.01 & 1.50 & 0.592 & 0.043 & +0.50 & 1.87 \\
\hline $18: 2(n-6)$ & 11.40 & 1.06 & 11.41 & 0.93 & +0.01 & 0.81 & 0.947 & 11.21 & 1.24 & 11.34 & 1.01 & $+0 \cdot \cdot 14$ & 1.03 & 0.280 & 0.249 & +0.13 & 1.27 \\
\hline $20: 4(n-6)$ & 12.56 & 1.21 & 12.41 & 1.01 & -0.15 & 0.91 & 0.192 & 12.46 & 1.41 & 12.44 & 1.23 & -0.02 & 0.85 & 0.878 & 0.374 & +0.13 & 1.19 \\
\hline Total $(n-3)$ PUFA & 6.59 & 1.19 & 6.55 & 0.74 & -0.05 & 1.00 & 0.585 & 6.39 & 0.83 & 6.43 & 0.74 & +0.04 & 0.46 & 0.400 & 0.964 & +0.09 & 1.17 \\
\hline $18: 3(n-3)$ & 0.19 & 0.07 & 0.26 & 0.08 & +0.07 & 0.07 & $\leq 0.0001$ & 0.19 & 0.08 & 0.26 & 0.07 & +0.07 & 0.06 & $\leq 0.0001$ & 0.467 & -0.01 & 0.08 \\
\hline $18: 4(n-3)$ & 0.09 & 0.08 & 0.09 & 0.06 & +0.00 & 0.09 & 0.310 & 0.08 & 0.05 & 0.08 & 0.04 & -0.01 & 0.05 & 0.037 & 0.061 & -0.01 & 0.10 \\
\hline $20: 5(n-3)$ & 0.61 & 0.27 & 0.64 & 0.28 & +0.03 & 0.22 & 0.092 & 0.60 & 0.31 & 0.64 & 0.27 & $\begin{array}{l}0.04 \\
+0.0\end{array}$ & 0.20 & 0.008 & 0.463 & +0.01 & 0.32 \\
\hline $22: 5(n-3)$ & 1.99 & 0.34 & 2.05 & 0.32 & +0.06 & 0.16 & 0.003 & 1.95 & 0.32 & 2.03 & 0.33 & +0.08 & 0.15 & $\leq 0.0001$ & 0.300 & +0.02 & 0.23 \\
\hline $22: 6(n-3)$ & 3.55 & 0.79 & 3.42 & 0.75 & -0.13 & 0.37 & 0.005 & 3.57 & 0.87 & 3.44 & 0.79 & -0.14 & 0.33 & 0.001 & 0.923 & -0.01 & 0.50 \\
\hline
\end{tabular}

* The two groups did not differ significantly with regard to any of the variables at baseline (paired Student's $t$ tests or Wilcoxon signed-rank tests).

$\dagger$ Treatment difference was calculated by (ALA + quercetin (endpoint - baseline)) - (ALA+ placebo (endpoint - baseline)). 


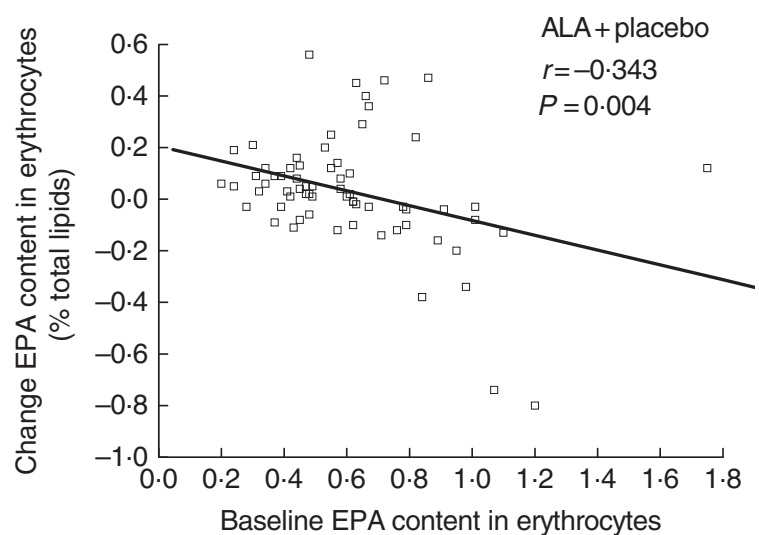

(\% total lipids)

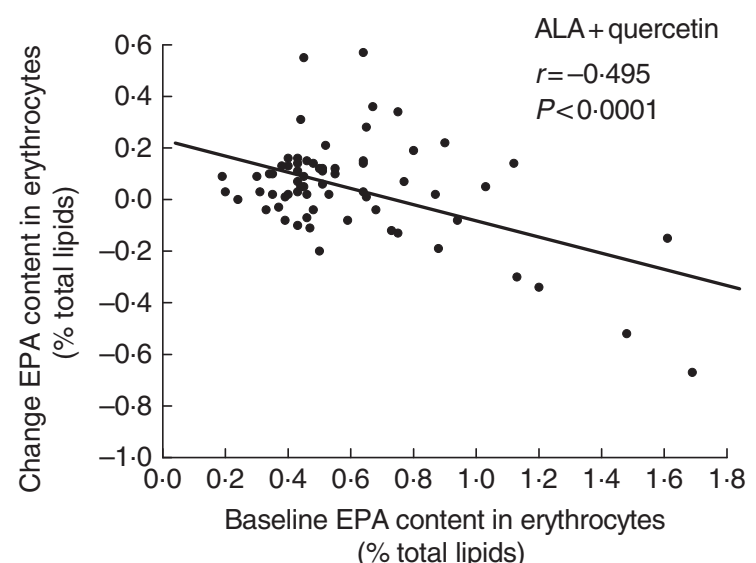

Fig. 6. Relationship between baseline EPA content in erythrocytes and change after 8 weeks, $a$-linolenic acid (ALA) +quercetin $(190 \mathrm{mg} / \mathrm{d})$ or, $\square$, ALA + placebo supplementation in metabolically healthy men and women (n 67). r, Pearson's rank correlation coefficient.

the lack of DHA increase in our study was not due to an inadequate dose of ALA.

An equally important point is that the intervention period of 8 weeks may have been too short to increase DHA content in erythrocytes. Because synthesis of DHA involves more steps than synthesis of $\mathrm{EPA}^{(37)}$, assessing the effect on DHA content likely requires longer duration of ALA supplementation. Accordingly, some studies suggest that DHA blood measures increase with long-term ALA supplementation (52 weeks) ${ }^{(50)}$.

Other studies have also shown a decreased proportion of DHA after an increase in dietary ALA intake ${ }^{(51,52)}$. DHA may also be retroconverted, causing ALA and C24:6 (n-3) to compete for $\Delta^{6}$-desaturase and resulting in EPA accumulation and limited synthesis and accumulation of DHA. This mechanism has been postulated in Hep-G2 phospholipids and previous human trials ${ }^{(53-57)}$. Studies estimate that $0.5-12 \%$ of DHA is retroconverted to $\mathrm{EPA}^{(12,58)}$. Moreover, in a few cases, the declines in EPA/DHA status might be declared by the exclusion of long-chain $n-3$ PUFA sources in the habitual diet of the participants.

\section{Effect of quercetin supplementation}

In the present study, quercetin did not significantly increase EPA in serum phospholipids and erythrocytes when compared with placebo, indicating that quercetin did not affect the conversion of ALA. Moderate wine drinking has been associated with increased levels of EPA and DHA in plasma fatty acids in epidemiological studies ${ }^{(15,59,60)}$, and a cohort study shows a significant association between erythrocyte levels of EPA and DHA in wine drinkers but not in beer or spirit drinkers ${ }^{(16)}$, which suggests that components in wine only, not ethanol, affect the metabolism of $n-3$ PUFA. Animal studies show that consumption of flavonoids increases conversion of ALA, further supporting the hypothesis that ethanol does not play a major role in the association between wine drinking and increased $n$-3 PUFA metabolism ${ }^{(17,61,62)}$. Quercetin, ubiquitous in plants, is among the most potent antioxidants of plant origin and a predominant flavonoid in human nutrition ${ }^{(18)}$. Flavonoids exert biological effects by modulation of mammalian cell signaling pathways ${ }^{(63-65)}$, and experimental studies demonstrate that quercetin interacts with PPAR $\alpha^{(19,20)}$, which may be a mechanism by which it influences $\Delta^{6}$-desaturase activity and conversion of ALA. Wu et al. ${ }^{(66)}$ reported that dietary consumption of ALA with the polyphenol curcumin increases EPA and DHA content in the rat liver and brain due to elevated activity of the required enzymes (i.e. $\Delta^{6}$-desaturase). The reason why quercetin supplementation did not modulate the $(n-3)$ PUFA elongation-desaturation pathway to increase EPA and DHA content in our study is unclear, although the relatively low bioavailability of quercetin in humans is a possible explanation. We demonstrated that, despite good compliance to quercetin supplementation, the plasma levels of quercetin were low (about $0.5 \mu \mathrm{mol} / \mathrm{l})^{(30,31,67)}$. In contrast to our study, the applied doses of flavonoids in cell culture and animal studies were higher (e.g. about $500 \mathrm{mg} / \mathrm{d}$ ) ${ }^{(62)}$. Thus, possibly a pharmacological dose is needed to exert similar effects in humans.

\section{Influence of sex}

We found no significant sex-related differences in serum phospholipid and erythrocyte fatty acid profiles at baseline, after the two treatments, or over the course of the intervention. Stable isotope tracer studies show that the conversion of ALA to EPA and DHA is greater in young women of child-bearing age than in men of similar age ${ }^{(12,21-25,68)}$. Childs et al. ${ }^{(27)}$ confirmed these findings in a re-examination of their data. The greater capacity of ALA to DHA conversion among women of childbearing age may be an evolutionary adaption to ensure an adequate supply of DHA for the fetus ${ }^{(37,69,70)}$. Regulation of $n-3$ fatty acid metabolism and the conversion rates of ALA may be influenced by oestrogen ${ }^{(26,27,44)}$, as the DHA concentration in maternal blood is significantly elevated during the third trimester of pregnancy when the circulating levels of oestrogen are highest ${ }^{(69,71)}$. In addition, erythrocyte DHA content is greater in women taking an oestradiol-based contraceptive pill than in women not taking oral contraceptives ${ }^{(72,73)}$. In the present study, we could not find any significant differences in contraceptive $v$. non-contraceptive users in ALA conversion. Oestrogen may regulate the expression and activity of desaturases and elongases through PPAR ${ }^{(26)}$. However, Sibbons et al. ${ }^{(74)}$ showed that physiological concentrations of progesterone caused increased mRNA expression of the key enzymes for ALA 
conversion in Hep-G2 cells, while oestrogen and testosterone had no significant effect. The reasons for the lack of sex-related differences in the present study are unclear. Decsi \& Kennedy ${ }^{(68)}$ postulated that sex explains only about $2 \%$ of the variability of plasma phospholipid DHA values. The regulation of PUFA metabolism is complex and includes genetic variations, dietary components and substrate competition ${ }^{(13)}$, whereby the lack of sex-related difference in the present study can be explained by heterogeneity and variance in PUFA metabolism.

\section{Strengths and limitations}

The major strengths of our study are the double-blinded, placebo-controlled, crossover design, relatively large sample size, low dropout rate and high compliance with the treatments. Furthermore, we examined the fatty acid composition of serum phospholipids and erythrocytes to depict short- and long-term changes, respectively, with the intervention. In addition, we examined both percentage fatty acid profiles and absolute concentrations of fatty acids in serum phospholipids. A potential limitation is that we did not measure $\Delta^{6}$-desaturase activity. Thus, we cannot confirm our hypothesis that increased conversion of ALA is due to increased $\Delta^{6}$-desaturase activity. Methods to measure $\Delta^{6}$-desaturase activity are complex and limited. The enzyme activity can be determined by taking subcutaneous adipose tissue or liver biopsies or estimations using product:substrate ratios of individual fatty acids. However, Sjögren et $a l .{ }^{(75)}$ showed that desaturation indices for $\Delta^{6}$-desaturase do not correlate with mRNA expression of the enzyme determined from biopsies. Another potential limitation might be the interference of the habitual diet of the participants. We included only subjects with sporadic intake of long-chain n-3 PUFA sources. However, the change in habitual diet, as a potential confounder, may account for some of the declines in EPA/DHA status.

\section{Conclusion}

The present study showed that daily supplementation with $3.6 \mathrm{~g} / \mathrm{d}$ ALA over 8 weeks improved $n$ - 3 long-chain PUFA status in metabolically healthy subjects. ALA supplementation increased ALA, EPA and DPA, but not DHA, in serum phospholipids and erythrocytes. The conversion of ALA was not affected by concomitant ingestion of a supra-nutritional dose of $190 \mathrm{mg} / \mathrm{d}$ quercetin. In addition, we did not find sex-specific differences in the responses to ALA intervention.

\section{Acknowledgements}

The authors are indebted to Anke Ernst, Christine Bierschbach and Petra Schulz for excellent technical assistance.

This study was supported by the Union for Promoting Oil and Protein Plants e.V. (UFOP). The UFOP had no role in the design, analysis or writing of this article.

C. B., P. S. and S. E. designed the study. B. Z. was the medical advisor. C. B. and S. E. recruited the subjects and performed the study. B. A. performed the blinding procedure. P. L. produced the capsules. C. B. performed the statistical calculations with help from R. F. and S. E. C. B., S. W., R. F., B. Z. and S. E. participated in data collection and blood analyses. C. B., P. S. and S. E. wrote the manuscript. All authors contributed to the final version.

None of the authors had a known conflict of interest.

\section{References}

1. Kromhout D (2012) Omega-3 fatty acids and coronary heart disease. The final verdict? Curr Opin Lipidol 23, 554-559.

2. Delgado-Lista J, Perez-Martinez $\mathrm{P}$, Lopez-Miranda $\mathrm{J}$, et al. (2012) Long chain omega-3 fatty acids and cardiovascular disease: a systematic review. Br J Nutr 107, 201-213.

3. Mozaffarian D, Lemaitre RN, King IB, et al. (2013) Plasma phospholipid long-chain omega-3 fatty acids and total and cause-specific mortality in older adults: the Cardiovascular Health Study. Ann Intern Med 158, 515-525.

4. Rajaram S (2014) Health benefits of plant-derived alphalinolenic acid. Am J Clin Nutr 100, 443-448.

5. Brouwer IA, Katan MB \& Zock PL (2004) Dietary alphalinolenic acid is associated with reduced risk of fatal coronary heart disease, but increased prostate cancer risk: a metaanalysis. J Nutr 134, 919-922.

6. Wang C, Harris WS, Chung M, et al. (2006) n-3 Fatty acids from fish or fish-oil supplements, but not alpha-linolenic acid, benefit cardiovascular disease outcomes in primary- and secondary-prevention studies: a systematic review. Am J Clin Nutr 84, 5-17.

7. Geleijnse JM, de Goede J \& Brouwer IA (2010) Alpha-linolenic acid: is it essential to cardiovascular health? Curr Atheroscler Rep 12, 359-367.

8. Pan A, Chen M, Chowdhury R, et al. (2012) $\alpha$-Linolenic acid and risk of cardiovascular disease: a systematic review and meta-analysis. Am J Clin Nutr 96, 1262-1273.

9. Barceló-Coblijn G \& Murphy EJ (2009) Alpha-linolenic acid and its conversion to longer chain $n$ - 3 fatty acids: benefits for human health and a role in maintaining tissue $n-3$ fatty acid levels. Prog Lipid Res 48, 355-374.

10. Gebauer SK, Psota TL, Harris WS, et al. (2006) n-3 Fatty acid dietary recommendations and food sources to achieve essentiality and cardiovascular benefits. Am J Clin Nutr $\mathbf{8 3}$, 1526-1535.

11. Stark AH, Crawford MA \& Reifen R (2008) Update on alphalinolenic acid. Nutr Rev 66, 326-332.

12. Burdge $G$ (2004) Alpha-linolenic acid metabolism in men and women: nutritional and biological implications. Curr Opin Clin Nutr Metab Care 7, 137-144.

13. Tu WC, Cook-Johnson RJ, James MJ, et al. (2010) Omega-3 long chain fatty acid synthesis is regulated more by substrate levels than gene expression. Prostaglandins Leukot Essent Fatty Acids 83, 61-68.

14. Tang C, Cho HP, Nakamura MT, et al. (2003) Regulation of human $\Delta-6$ desaturase gene transcription: identification of a functional direct repeat-1 element. J Lipid Res 44, 686-695.

15. de Lorgeril M, Salen P, Martin J-L, et al. (2008) Interactions of wine drinking with omega-3 fatty acids in patients with coronary heart disease: a fish-like effect of moderate wine drinking. Am Heart J 155, 175-181.

16. di Giuseppe R, de Lorgeril MD, Salen P, et al. (2009) Alcohol consumption and $n-3$ polyunsaturated fatty acids in healthy men and women from 3 European populations. Am J Clin Nutr 89, 354-362.

17. Toufektsian M-C, Salen P, Laporte F, et al. (2011) Dietary flavonoids increase plasma very long-chain $(n-3)$ fatty acids in rats. J Nutr 141, 37-41. 
18. Crozier A, Jaganath IB \& Clifford MN (2009) Dietary phenolics: chemistry, bioavailability and effects on health. Nat Prod Rep 26, 1001-1043.

19. Castrejón-Tellez V, Rodríguez-Pérez JM, Pérez-Torres I, et al. (2016) The effect of resveratrol and quercetin treatment on PPAR mediated uncoupling protein (UCP-) 1, 2, and 3 expression in visceral white adipose tissue from metabolic syndrome rats. Int J Mol Sci 17, E1069.

20. Sun X, Yamasaki M, Katsube T, et al. (2015) Effects of quercetin derivatives from mulberry leaves: improved gene expression related hepatic lipid and glucose metabolism in short-term high-fat fed mice. Nutr Res Pract 9, 137-143.

21. Emken EA, Adlof RO \& Gulley RM (1994) Dietary linoleic acid influences desaturation and acylation of deuterium-labeled linoleic and linolenic acids in young adult males. Biochim Biophys Acta 1213, 277-288.

22. Burdge GC \& Wootton SA (2002) Conversion of alpha-linolenic acid to eicosapentaenoic, docosapentaenoic and docosahexaenoic acids in young women. BrJ Nutr 88, 411-420.

23. Pawlosky R, Hibbeln J, Lin Y, et al. (2003) n-3 Fatty acid metabolism in women. Br J Nutr 90, 993-995.

24. Burdge GC, Finnegan YE, Minihane AM, et al. (2003) Effect of altered dietary $n-3$ fatty acid intake upon plasma lipid fatty acid composition, conversion of [13C]alpha-linolenic acid to longer-chain fatty acids and partitioning towards betaoxidation in older men. Br J Nutr 90, 311-321.

25. Hussein N, Ah-Sing E, Wilkinson P, et al. (2005) Long-chain conversion of [13C]linoleic acid and alpha-linolenic acid in response to marked changes in their dietary intake in men. J Lipid Res 46, 269-280.

26. Kitson AP, Stroud CK \& Stark KD (2010) Elevated production of docosahexaenoic acid in females: potential molecular mechanisms. Lipids 45, 209-224.

27. Childs CE, Kew S, Finnegan YE, et al. (2014) Increased dietary $\alpha$-linolenic acid has sex-specific effects upon eicosapentaenoic acid status in humans: re-examination of data from a randomised, placebo-controlled, parallel study. Nutr J 13, 1-5.

28. Linseisen J, Radtke J \& Wolfram G (1997) Flavonoidzufuhr Erwachsener in einem bayerischen Teilkollektiv der Nationalen Verzehrsstudie (Flavonoid intake of adults in a Bavarian subgroup of the national food consumption survey). $Z$ Ernabrungswiss 36, $403-412$

29. Zamora-Ros R, Forouhi NG, Sharp SJ, et al. (2014) Dietary intakes of individual flavanols and flavonols are inversely associated with incident type 2 diabetes in European populations. J Nutr 144, 335-343.

30. Egert S, Wolffram S, Schulze B, et al. (2012) Enriched cereal bars are more effective in increasing plasma quercetin compared with quercetin from powder-filled hard capsules. Br J Nutr 107, 539-546.

31. Burak C, Brüll V, Langguth P, et al. (2017) Higher plasma quercetin levels following oral administration of an onion skin extract compared with pure quercetin dihydrate in humans. Eur J Nutr 56, 343-353.

32. Sun S, Chumlea W, Heymsfield S, et al. (2003) Development of bioelectrical impedance analysis prediction equations for body composition with the use of a multicomponent model for use in epidemiological surveys. Am J Clin Nutr 77, 331-340.

33. Folch J, Lees M \& Sloane Stanley GH (1957) A simple method for the isolation and purification of total lipides from animal tissues. J Biol Chem 226, 497-509.

34. Christophe A \& Matthijs F (1967) New method for the determination of the fatty acid pattern of serum lipid classes. Clin Chim Acta 16, 39-43.
35. Bhagwat S, Haytowitz D \& Holden J (2013) US DA Database for the flavonoid content of selected foods, release 3.1. US Department of Agriculture. http//www ars usda gov/Services/ docs htm?docid=6231 (accessed December 2013).

36. Kenward MG \& Jones B (1987) The analysis of data from $2 \times 2$ cross-over trials with baseline measurements. Stat Med $\mathbf{6}$, 911-926.

37. Burdge GC \& Calder PC (2005) $\alpha$-Linolenic acid metabolism in adult humans: the effects of gender and age on conversion to longer-chain polyunsaturated fatty acids. Eur J Lipid Sci Technol 107, 426-439.

38. Plourde M \& Cunnane SC (2007) Extremely limited synthesis of long chain polyunsaturates in adults: implications for their dietary essentiality and use as supplements. Appl Physiol Nutr Metab 32, 619-634.

39. Mantzioris E, James MJ, Gibson RA, et al. (1994) Dietary substitution with an alpha-linolenic acid rich vegetable oil increases eicosapentaenoic acid concentrations in tissues. Am J Clin Nutr 59, 1304-1309.

40. Li D, Sinclair A, Wilson A, et al. (1999) Effect of dietary alphalinolenic acid on thrombotic risk factors in vegetarian men. Am J Clin Nutr 69, 872-882.

41. Finnegan YE, Minihane AM, Leigh-Firbank EC, et al. (2003) Plant- and marine-derived $n-3$ polyunsaturated fatty acids have differential effects on fasting and postprandial blood lipid concentrations and on the susceptibility of L to oxidative modification in moderately hyperlipidemic subjects. Am J Clin Nutr 77, 783-795.

42. Wallace FA, Miles EA \& Calder PC (2003) Comparison of the effects of linseed oil and different doses of fish oil on mononuclear cell function in healthy human subjects. Br J Nutr 89 , 679-689.

43. Harper CR, Edwards MJ, DeFilipis AP, et al. (2006) Flaxseed oil increases the plasma concentrations of cardioprotective $(n-3)$ fatty acids in humans. J Nutr Dis 136, 83-87.

44. Egert S, Kannenberg F, Somoza V, et al. (2009) Dietary alpha-linolenic acid, EPA, and DHA have differential effects on LDL fatty acid composition but similar effects on serum lipid profiles in normolipidemic humans. J Nutr 139, 861-868.

45. Egert S, Lindenmeier M, Harnack K, et al. (2012) Margarines fortified with a -linolenic Acid, eicosapentaenoic acid, or docosahexaenoic acid alter the fatty acid composition of erythrocytes but do not affect the antioxidant status of healthy adults. J Nutr 142, 1638-1644.

46. Freemantle E, Vandal M, Tremblay-Mercier J, et al. (2006) Omega3 fatty acids, energy substrates, and brain function during aging. Prostaglandins Leukot Essent Fatty Acids 75, 213-220.

47. Burdge GC \& Calder PC (2006) Dietary alpha-linolenic acid and health-related outcomes: a metabolic perspective. Nutr Res Rev 19, 26-52.

48. Brenna JT, Salem N, Sinclair AJ, et al. (2009) Alpha-linolenic acid supplementation and conversion to $n$-3 long-chain polyunsaturated fatty acids in humans. Prostaglandins Leukot Essent Fatty Acids 80, 85-91.

49. Barceló-Coblijn G, Murphy EJ, Othman R, et al. (2008) Flaxseed oil and fish-oil capsule consumption alters human red blood cell $n-3$ fatty acid composition: a multiple-dosing trial comparing 2 sources of $n-3$ fatty acid. Am J Clin Nutr 88, 801-809.

50. Bemelmans WJE, Broer J, Feskens EJM, et al. (2002) Effect of an increased intake of alpha-linolenic acid and group nutritional education on cardiovascular risk factors: the Mediterranean Alpha-linolenic Enriched Groningen Dietary Intervention (MARGARIN) study. Am J Clin Nutr $\mathbf{7 5}$, 221-227. 
51. Weaver BJ, Corner EJ, Bruce VM, et al. (1990) Dietary canola oil: effect on the accumulation of eicosapentaenoic acid in the alkenylacyl fraction of human platelet ethanolamine phosphoglyceride. Am J Clin Nutr 51, 594-598.

52. Kew S, Banerjee T, Minihane AM, et al. (2003) Lack of effect of foods enriched with plant- or marine-derived $n-3$ fatty acids on human immune function. Am J Clin Nutr 77, 1287-1295.

53. Conquer JA \& Holub BJ (1997) Dietary docosahexaenoic acid as a source of eicosapentaenoic acid in vegetarians and omnivores. Lipids 32, 341-345.

54. Vidgren HM, Ågren JJ, Schwab U, et al. (1997) Incorporation of $n-3$ fatty acids into plasma lipid fractions, and erythrocyte membranes and platelets during dietary supplementation with fish, fish oil, and docosahexaenoic acid-rich oil among healthy young men. Lipids 32, 697-705.

55. Hansen J-B, Grimsgaard S, Nilsnen H, et al. (1998) Effects of highly purified eicosapentaenoic acid and docosahexaenoic acid on fatty acid absorption, incorporation into serum phospholipids and postprandial triglyceridemia. Lipids 33, 131-138.

56. Portolesi R, Powell BC, Gibson RA, et al. (2007) Competition between $24: 5 n-3$ and ALA for $\Delta 6$ desaturase may limit the accumulation of DHA in HepG2 cell membranes. J Lipid Res 48, 1592-1598

57. Egert S, Somoza V, Kannenberg F, et al. (2007) Influence of three rapeseed oil-rich diets, fortified with $\alpha$-linolenic acid, eicosapentaenoic acid or docosahexaenoic acid on the composition and oxidizability of low-density lipoproteins: results of a controlled study in healthy volunteers. Eur J Clin Nutr $\mathbf{6 1}$, 314-325.

58. Gerster H (1998) Can adults adequately convert alphalinolenic acid (18:3n-3) to eicosapentaenoic acid (20:5n-3) and docosahexaenoic acid (22:6n-3)? Int J Vitam Nutr Res 68 , 159-173.

59. Di Castelnuovo A, Rotondo S, Iacoviello L, et al. (2002) Metaanalysis of wine and beer consumption in relation to vascular risk. Circulation 105, 2836-2844.

60. de Lorgeril M, Salen P, Martin J-L, et al. (2002) Wine drinking and risks of cardiovascular complications after recent acute myocardial infarction. Circulation 106, 1465-1469.

61. Graf D, Seifert S, Jaudszus A, et al. (2013) Anthocyanin-rich juice lowers serum cholesterol, leptin, and resistin and improves plasma fatty acid composition in Fischer rats. PLOS ONE 8, 1-5.

62. Vauzour D, Tejera N, O'Neill C, et al. (2015) Anthocyanins do not influence long-chain $n-3$ fatty acid status: studies in cells, rodents and humans. J Nutr Biochem 26, 211-218.
63. Williams RJ, Spencer JPE \& Rice-Evans C (2004) Flavonoids: antioxidants or signalling molecules? Free Radic Biol Med 36, 838-849.

64. Mezei O, Li Y, Mullen E, et al. (2006) Dietary isoflavone supplementation modulates lipid metabolism via PPARalpha-dependent and -independent mechanisms. Physiol Genomics 26, 8-14.

65. Avior Y, Bomze D, Ramon O, et al. (2013) Flavonoids as dietary regulators of nuclear activity. Food Funct 4, 831-844.

66. Wu A, Noble EE, Tyagi E, et al. (2015) Curcumin boosts DHA in the brain: implications for the prevention of anxiety disorders. Biochim Biophys Acta 1852, 951-961.

67. Brüll V, Burak C, Stoffel-Wagner B, et al. (2015) Effects of a quercetin-rich onion skin extract on $24 \mathrm{~h}$ ambulatory blood pressure and endothelial function in overweight-to-obese patients with (pre-)hypertension: a randomised double-blinded placebo-controlled cross-over trial. Br J Nutr 114, 1263-1277.

68. Decsi T \& Kennedy K (2011) Sex-specific differences in essential fatty acid metabolism. Am J Clin Nutr 94, 1914-1919.

69. Stark KD, Beblo S, Murthy M, et al. (2005) Comparison of bloodstream fatty acid composition from African-American women at gestation, delivery, and postpartum. J Lipid Res $\mathbf{4 6}$, $516-525$.

70. Innis SM (2005) Essential fatty acid transfer and fetal development. Placenta 26, 70-75.

71. Rump P, Otto SJ \& Hornstra G (2001) Leptin and phospholipid-esterified docosahexaenoic acid concentrations in plasma of women: observations during pregnancy and lactation. Eur J Clin Nutr 55, 244-251.

72. Giltay EJ, Gooren LJG, Toorians AWFT, et al. (2004) Doco sahexaenoic acid concentrations are higher in women than in men because of estrogenic effects. Am J Clin Nutr $\mathbf{8 0}$, $1167-1174$

73. Magnusardottir AR, Steingrimsdottir L, Thorgeirsdottir H, et al. (2009) Docosahexaenoic acid in red blood cells of women of reproductive age is positively associated with oral contraceptive use and physical activity. Prostaglandins Leukot Essent Fatty Acids 80, 27-32.

74. Sibbons CM, Brenna JT, Lawrence P, et al. (2014) Effect of sex hormones on $n-3$ polyunsaturated fatty acid biosynthesis in HepG2 cells and in human primary hepatocytes. Prostaglandins Leukot Essent Fatty Acids 90, 47-54.

75. Sjögren P, Sierra-Johnson J, Gertow K, et al. (2008) Fatty acid desaturases in human adipose tissue: relationships between gene expression, desaturation indexes and insulin resistance. Diabetologia 51, 328-335. 